\title{
Anti-CD22 Antibody-drug Conjugate
}

National Cancer Institute

\section{Source}

National Cancer Institute. Anti-CD22 Antibody-drug Conjugate. NCI Thesaurus. Code C155713.

An antibody-drug conjug ate (ADC) directed ag ainst the CD22 antigen. 